\title{
Investigation and Analysis of the Catastrophic Failure of an Offshore Water Injector Well
}

\author{
Ramesh Ramasamy ${ }^{1, *}$ \\ ${ }^{1}$ Azakti Energy Sdn. Bhd., Bukit Bintang, 55100 Kuala Lumpur, Malaysia.
}

\begin{abstract}
The catastrophic failure of an offshore water injector well is presented in this paper. The failure mode was determined from the final collapsed state of the conductor pipe which resulted in the surface Xmas tree and wellhead to drop vertically down onto the platform deck. Various inspections and assessments are carried out to determine the integrity of the well structure and compared against the original drilling records. Stability evaluations of the casing is also carried out to account for the loss of annular cement which resulted in loss of centralisation. The analyses conclude that various sequence of events have contributed towards the failure of this well. The lack of intermediate inspections and monitoring have resulted in uninhibited corrosion and pitting on the conductor pipe. Some considerations on the necessity of an effective inspections strategy and rationalisations of a robust integrity screening are also drawn.
\end{abstract}

\section{Introduction}

The catastrophic failure of an offshore water injector well is investigated in this paper. A typical offshore well construction as part of a jacket platform consists of an outer conductor pipe, surface casing, inner casing and a tubing. The annular spaces between these concentric pipes are labelled as annuli $\mathrm{A}, \mathrm{B}$ and $\mathrm{C}$ respectively, with the tubing supported downhole by a packer. The outer hole of the conductor is cemented to the seabed, whereas the $\mathrm{C}$-annulus is ideally cemented to the surface, just below the wellhead flange. The B and A annuli are cemented adequately to provide centralisations. The conductor is also restrained laterally by the platform through the conductor guides, and at the lower deck by a cover plate arrangement.

The inspection of the well failure, at the topside level from the lower deck is shown in Fig 1, highlighting the surface tree vertically settling down onto the lower deck, (a) damaging the valves, (b) and subsequently damaging the flange and piping assemblies.

Further inspections on the conductor and the C-annulus are shown in Figure 2 and Figure 3. The excessive corrosion is immediately identified throughout the conductor, and at the conductor guide located near the splash zone region (approximately $1 \mathrm{~m}$ to $2 \mathrm{~m}$ above MSL), structural collapse is observed due to excessive corrosion and complete loss of sectional stiffness. The borescope insertion shows a significant cement shortfall (absence of cement) and severe corrosion on the surface casing and the inside wall of the conductor,

*Corresponding author: ramesh.ramasamy@,azakti-energy.com 
with evidence of rust flake formation and major wall loss on the metallic surfaces. Diver based subsea inspection of the conductor pipe below MSL was carried out and came back with observation of thick marine growth (approximately $25 \mathrm{~mm}$ thick), thus insignificant corrosion beneath the sea level was concluded. The present investigation will revolve around engineering assessments of the platform conductor of a water injection well, and discussion on the various contributing factors and the progressive failure which affected this well.

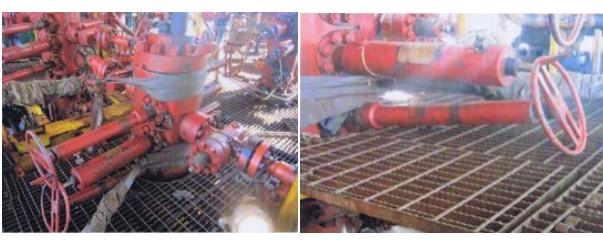

(a)

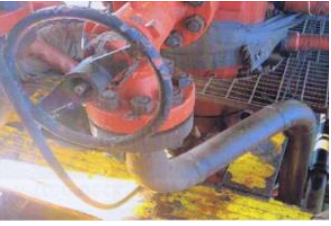

(b)

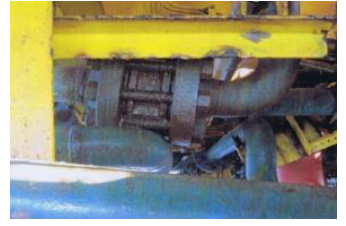

Fig 1. Topside Inspection of the Well Failure

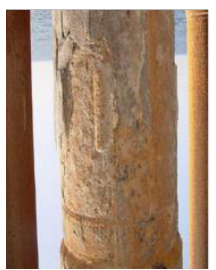

Fig. 2. Conductor Corrosion and Damage Inspection

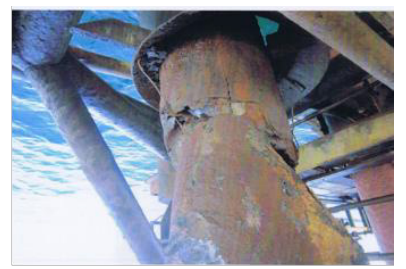

Fig. 3. Borescope Camera Inspection inside the C-Annulus

\section{Engineering assessments}

\subsection{Well and field data}

The well construction data, extracted from the original drilling records are summarised in Table 1[1], and the topside equipment weights are 1Te, 6Te and 4Te for the Wellhead, BOP and tree respectively. The water depth and deck height (air gap) are $15 \mathrm{~m}$ each. The conductor corrosion inspection is shown in Fig 4 for both the minimum and average readings from the 8-point ultrasonic pulse echo [2] readings at every $1 \mathrm{~m}$ elevation, down to the MSL. The conductor wall thicknesses below the splash zone region is assumed to be nominal. The cement inside the $\mathrm{C}$ and $\mathrm{B}$ annuli will be ignored as a conservative measure for now, since the borescope insertion found no traces of cement remaining. The benign environmental conditions existing on site exhibits a maximum surface current of $0.5 \mathrm{~m} / \mathrm{s}$ and maximum wave height of $8 \mathrm{~m}$ over $9 \mathrm{~s}$ period under extreme storm conditions. The set depths for the strings below the wellhead for the conductor, surface casing, inner casing and tubing are $80 \mathrm{~m}, 1710 \mathrm{~m}, 3100 \mathrm{~m}$ and $3000 \mathrm{~m}$ respectively. 
Table 1. Well construction data

\begin{tabular}{|c|c|c|c|c|c|c|}
\hline \multicolumn{7}{|c|}{ Conductor, Casings, Tubing } \\
\hline \multirow{2}{*}{ Pipe } & Outer Diameter & \multicolumn{2}{|c|}{ Weight } & \multicolumn{2}{|c|}{ Yield Strength } \\
\cline { 2 - 7 } & in & $m m$ & $l b / f t$ & $\mathrm{~kg} / \mathrm{m}$ & $k s i$ & $M P a$ \\
\hline 30in & 30 & 762 & 272 & 405 & 35.5 & 244 \\
\hline 13-3/8in & 13.375 & 340 & 68 & 101 & 55 & 379 \\
\hline 9-5/8in & 9.625 & 244 & 47 & 70 & 75 & 517 \\
\hline 3-1/2in & 3.5 & 89 & 9.2 & 13.7 & 80 & 551 \\
\hline
\end{tabular}

\subsection{Structural evaluations}

\subsubsection{Conductor Integrity}

Based on the methods proposed in [3], the well construction loads in the axial direction can be calculated by considering pipe stiffness and well equipment weights, such that the conductor, casings and tubing are analogous to axial springs in parallel arrangements supporting common topside loads, shown in Figure 5 where the terms $K_{i}$ represent the axial spring stiffness and $W_{i}$ is the effective buoyant weights of the $i$-th string. The total axial compression acting $\left(F_{i, j}\right)$ on the conductor at stage $j$ of the drilling sequence can be conservatively evaluated to be

$$
F_{1, v i i}=W_{2}+K_{1}\left[\frac{\left(W_{w h}+W_{b o p}+W_{3}\right)}{K_{1}+K_{2}}+\frac{W_{4}}{K_{1}+K_{2}+K_{3}}+\frac{\left(W_{t r e e}-W_{b o p}\right)}{K_{1}+K_{2}+K_{3}+K_{4}}\right]
$$

The global analysis of the two-dimensional well system is carried out in the nonlinear FE [4] by modelling the conductor and subsequent casing as concentric pipe-in-pipe assembly. The evaluated construction load is modelled as a concentrated downwards force at the top of the conductor.

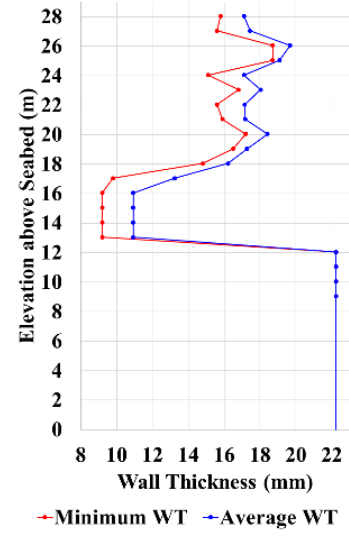

Fig 4. Conductor wall corrosion inspection

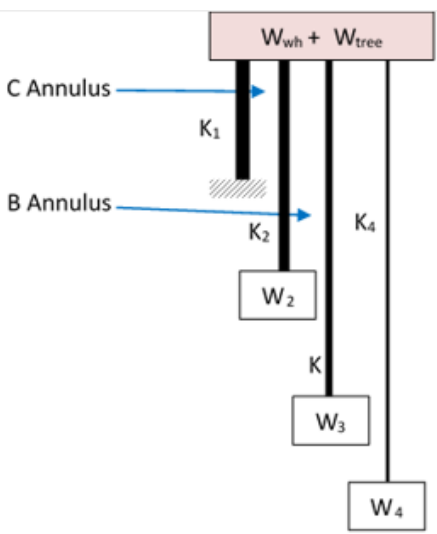

Fig 5. Platform well free body diagram

\subsubsection{Surface casing integrity}

The absence of cement inside the $\mathrm{C}$-annulus, along with the loss of effective wall of the surface casing due to corrosion need to be assessed for sinusoidal and helical buckling. The large vertical free span of the surface casing, which is supporting the topside weights is at risk of slumping in the cement shortfall region and the method proposed initially for coiled 
tubing operations in [5] is employed to provide an insight into this. For the surface casing's weight per length of $W$, the sinusoidal buckling force is empirically derived to be $2.55(E I W 2)^{I / 3}$ where $E$ and $I$ are the elastic modulus and area moment respectively. The equivalent joint length or free span length $(L)$ can then be calculated based on the buckling force from this expression, and the corresponding pitch length $(p)$ of the buckle formation can then be estimated based on the eccentricity of the surface casing on the conductor, $e$ and the axial compressive force acting at the top of the surface casing, $F$, and will lead to the vertical drop of the wellhead and tree by a magnitude $\Delta L$, such that

$$
\Delta L=L\left[\sqrt{\left(\frac{2 \pi r}{p}\right)^{2}+1}-1\right], \text { where } p=\sqrt{\frac{8 \pi^{2} E I}{F}}
$$

The post-buckling contact forces which is generated from the surface casing outer wall against the conductor inner wall will be generated, and the coiling will result in additional bending stresses on the casing. The total stress, combining the axial component can then be calculated and the stress utilisation can be drawn based on material strength.

\subsubsection{Annular cement integrity}

To account for further uncertainty of the condition of the annuli cement below the seabed elevations, several cement elevations are considered for assessment purposes ranging from 0m (no shortfall) to $1700 \mathrm{~m}$ (full length shortfall) cement elevations. This will enable the surface casing free span assessments for sinusoidal buckling inside the conductor bore.

Local cement assessments are also carried out. This involves the cracking and spalling of the cement which results in loss of cement bond to the steel surface. The presence of excessive corrosion and formation of rust flakes reduces if not completely diminishes the cement bond strength. In order to evaluate the characteristic bond strength of the remaining cement, empirical relationships which are presented in [6] will be used.

\section{Results}

Following the existing well records and inspections carried out on the failed injector well, the assessment are carried out and presented in this section. The compressive axial load at the top of the conductor and surface casing imparted the topside weights and subsequent strings are evaluated for a series of cement shortfalls inside both $\mathrm{C}$ and $\mathrm{B}$ annuli. The loads are calculated considering the worst possible compression acting on the conductor and the surface casing independently to enable separate assessments to investigate the overloading which caused the well failure. The load on the conductor is observed to increase by about $30 \%$ for the $\mathrm{C}$-annulus cement shortfall of $0 \mathrm{~m}$ to $1700 \mathrm{~m}$, whereas this does not affect the surface casing axial load. The shortfall inside the B-annulus also results in similar changes on the conductor as well as the surface casing. Based on detailed inspections on nearby wells inside the B-annulus, cement has been found in good state and an estimate of Cannulus shortfall of $200 \mathrm{~m}$ is realistically drawn, thus resulting in the conductor axial load of $3500 \mathrm{kN}$, and surface casing axial load of $2200 \mathrm{kN}$. These values will be used in the global analysis of the well system.

The global analysis of the well systems is then carried out to determine the bending moment distribution for both nominal wall thickness and in the corroded state (based on minimum wall thickness), and is extracted and presented in Fig. 6. Only a small difference in bending moment peaks are noticed for the corroded and uncorroded states as the bending stiffness changes are insignificant on a global scale. The nominal bending stiffness of the 
surface casing being only $5 \%$ of that of the conductor is expected to experience insignificant bending and therefore omitted.

The total stress is now calculated (Figure 7), combining the absolute magnitudes of the axial and bending stresses and the yield strength utilisation for both the conductor can be computed based on the recommended practise [7] and the resulting values are observed for exceedance of the allowable limits suggested therein. This shows the dominating effect is from the axial stress and the severe wall loss, which raises the overall stresses at the splash zone region to exceed the yield strength of the conductor material resulting in the sectional collapse.

The integrity of the surface casing is now assessed as described earlier. This involves the surface casing sinusoidal buckling inside the conductor bore which lead to the wellhead and tree to vertically settle onto the lower platform deck. First, the sinusoidal buckling threshold free span length is evaluated, along with the representative pitch length of the coil formations. This is followed by the consideration of corrosion on the surface casing and loss of centralisation in the absence of annular cement which can result in eccentricity of anywhere from a nominal of $2 \mathrm{in}(51 \mathrm{~mm})$ to a maximum of $7.4 \mathrm{in}(188 \mathrm{~mm})$ as seen from inspections of other nearby wells. These are depicted in Fig. 8 .

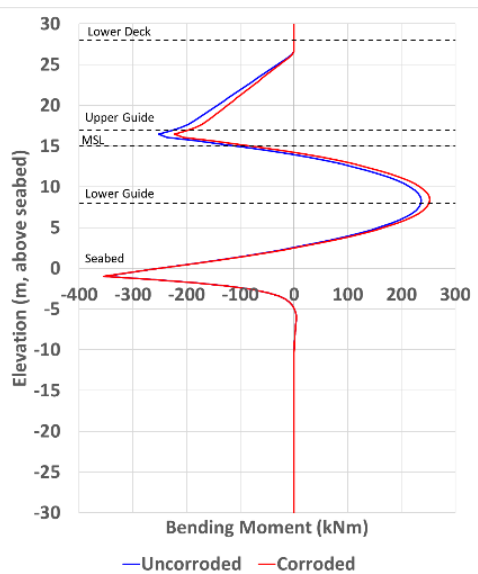

Fig. 6. Bending moment distribution

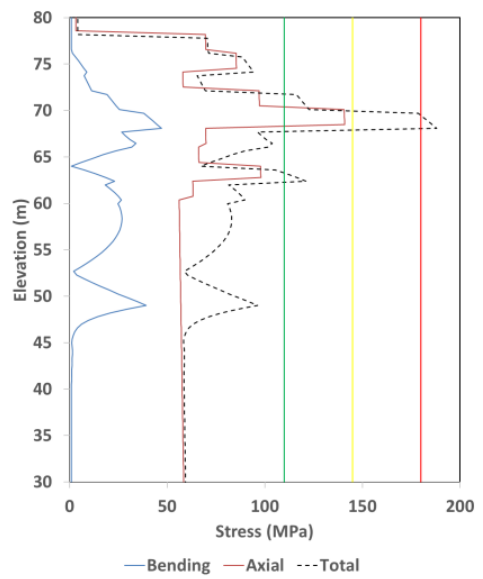

Fig. 7. Stress distribution

Based on the plots in Fig. $\boldsymbol{8}$, it is evident that a cement shortfall inside the C-annulus by about $80 \mathrm{~m}$ can present a potential risk of surface casing free span buckling. The casing eccentricity inside the conductor due to loss of cement is shown for several corrosion scenarios and for a surface casing average corrosion of $20 \%$ wall thickness loss, the wellhead vertical drop of $200 \mathrm{~mm}$ to $1200 \mathrm{~mm}$ can be expected. In the present case study, the wellhead drop of about $600 \mathrm{~mm}$ was evident from inspection and falls within this estimated range. The severity of the buckling on the surface casing can be further assessed in terms of the additional bending stress introduced when the coil formations take place. This additional bending stress, can be combined with the surface casing axial components to evaluate the total stress for each corrosion scenario, and is presented in Fig. 9. The uncentralised surface casing presents the most critical post-buckling behaviour, having larger bending stresses which in turn results in exceedance of the allowable limits. 

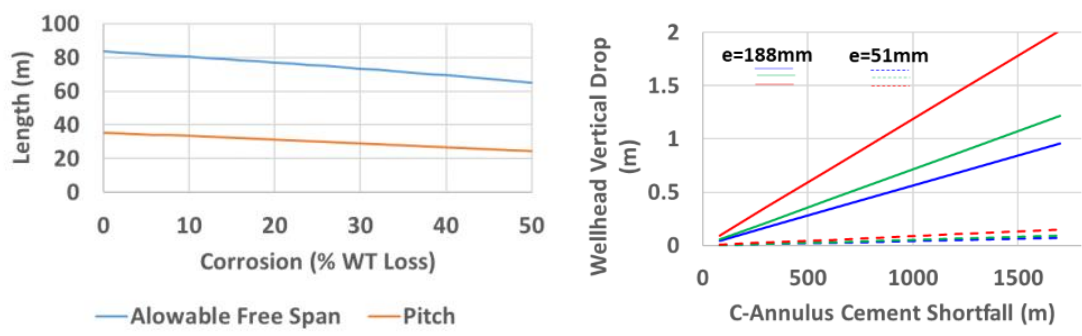

Fig. 8. Surface Casing Buckling Threshold
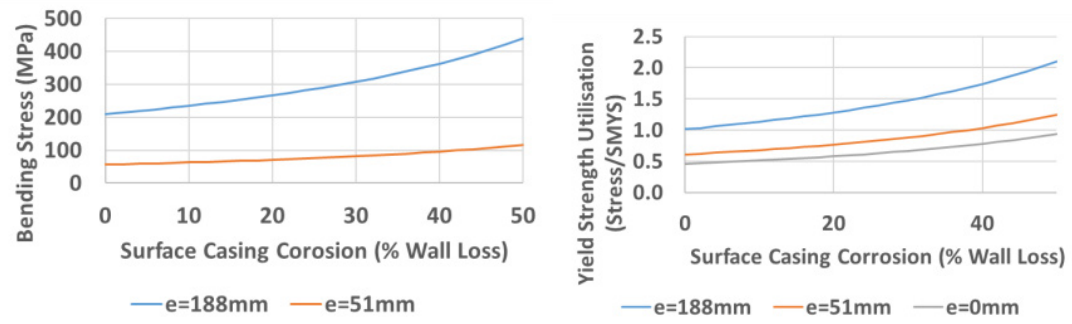

Fig. 9. Surface casing post-buckling analyses

It is evident from this that the surface casing, which was originally designed to support the topside weight has also collapse downhole inside the conductor, resulting in the wellhead to be displaced vertically onto the conductor, which subsequently overloaded at the splash zone region due to very high corroded wall loss.

\section{Conclusion}

From the assessments conducted, the following sequence of events can be pictured conclusively:

- Continuous corrosion on the conductor at the splash zone region is not monitored adequately and this results in severe wall loss at this section, causing pitting and seawater ingress into the $\mathrm{C}$-annulus;

- Internal corrosion of the conductor wall produced inward-expanding corrosion products which exerted pressure onto the cement and resulted in overstressing along the hoop direction to exceed the tensile limit, resulting in cement cracking;

- The presence of axial compressive load from the well topside equipment and other subsequent casing/tubing string played an important role in overloading the conductor and surface casing r4esulting in casing collapse;

- This resulted in the wellhead and tree to vertically drop down onto the lower platform deck.

The continued monitoring of other wells within the same age group has been recommended on the wellhead drop and conductor loads [8] and the monitoring of conductor corrosion at the splash zone region is being put into effect. A set of criteria for minimum wall thickness required on the conductor is also generated to ensure sufficient resistance to the well loads. 


\section{References}

1. American Petroleum Institute (API) Specification (5CT), "Specification for Casing and Tubing", 9, July (2011)

2. American Society for Testing and Materials, (ASTM E114-15), "Standard Practice for Ultrasonic Pulse-Echo Straight-Beam Contact Testing”, ASTM International, West Conshohocken, PA, (2015)

3. B. Stahl, M.P. Baur, Design Methodology for Offshore Platform Conductors, Offshore Technology Conference (OTC 1980), 5 May, Houston, Texas (1980).

4. Abaqus Theory Manual, Version 6.11 (2011).

5. Jiang Wu, H.C. Juvkam-Wold, Coiled Tubing Buckling Implications and Completing Horizontal Wells, SPE Drilling and Completions, March (1995)

6. U.K Department of Energy, "Grouted and Mechanical Strengthening and Repair of Tubular Steel Offshore Structures”. UK Department of Energy, Offshore Technology Report OTH 88283.

7. American Petroleum Institute (API-RP-2A WSD), 21st Edition, "Recommended Practice for Planning, Designing and Constructing Fixed Offshore Platforms", December (2000).

8. R. Ramasamy, Z. Ibrahim, H.K Chai, T.F Chau, "Measurement of platform conductor preload in streamlining the life extensions of ageing offshore wells", Applied Ocean Research 65, April, Pages 12-22, ISSN 0141-1187, http://doi.org/10.1016/j.apor.2017.03.004, (2017) 